\title{
QUALIDADE FÍSICO-QUÍMICA E SENSORIAL DE ABACAXI MINIMAMENTE PROCESSADO E IRRADIADO
}

\author{
EVELISE MONCAIO MODA* \\ LUCIMEIRE PILON** \\ SILVIO SANDOVAL ZOCCHI \\ MARTA HELENA FILLET SPOTO****
}

\begin{abstract}
O presente trabalho teve como objetivo monitorar a qualidade físico-química e sensorial de abacaxi cv. 'Smooth Cayenne' minimamente processado e submetido à radiação gama. Os frutos foram descascados, fatiados em rodelas e sanificados com $20 \mathrm{mg} . \mathrm{L}^{-1}$ de cloro ativo. As fatias foram acondicionadas em bandejas de poliestireno recobertas com filme flexível de policloreto de vinila (PVC) e irradiadas com 1 e $2 \mathrm{kGy}$, sendo o controle não-irradiado. As amostras foram armazenadas a temperatura de $5 \pm 1^{\circ} \mathrm{C}$ e avaliadas no primeiro, terceiro e sexto dias de armazenamento quanto à coloração, firmeza, sólidos solúveis (SS), acidez total titulável (ATT), pH e análise sensorial. O controle apresentou os menores valores de acidez e manutenção do $\mathrm{pH}$ em todas as avaliações, enquanto que o teor de sólidos solúveis foi maior na primeira avaliação para as doses de 1 e 2 kGy, decaindo com o decorrer do período de armazenamento. A irradiação não afetou a coloração dos abacaxis minimamente processados no período de avaliação, porém reduziu a firmeza das amostras na dose de 1 kGy. O controle apresentou as melhores notas nas avaliações sensoriais para os atributos aroma, sabor, textura e aparência. De maneira geral, os melhores resultados foram observados para o abacaxi minimamente processado não-irradiado (controle), sendo que as amostras irradiadas com 1 kGy obtiveram resultados inadequados para as análises de sólidos solúveis, acidez total titulável, pH, firmeza e sensorial.
\end{abstract}

PALAVRAS-CHAVE: ABACAXI; PROCESSAMENTO MÍNIMO; IRRADIAÇÃO; CONSERVAÇÃO.

* Doutora em Ciências, Centro de Energia Nuclear na Agricultura (CENA/USP), Piracicaba, SP (e-mail: emmoda@terra.com.br).

** Doutora em Ciências, CENA/USP, Piracicaba, SP (e-mail: lucimeire.pilon@yahoo.com.br).

*** Professor, Departamento de Ciências Exatas, Escola Superior de Agricultura "Luiz de Queiroz" (ESALQ/ USP), Piracicaba, SP (e-mail: sszocchi@esalq.usp.br).

**** Professora, Departamento de Agroindústria, Alimentos e Nutrição, ESALQ/USP, Piracicaba, SP (e-mail: mhfspoto@esalq.usp.br). 


\section{INTRODUÇÃO}

O abacaxi (Ananas comosus) apresenta excelente qualidade sensorial, atribuída à presença de açúcares, ácidos orgânicos e compostos voláteis, que lhe confere sabor e aroma característicos (ANDRADE, 1999). É cultivado em diversas regiões tropicais e subtropicais, e apreciado em todo o mundo. Segundo dados do Anuário da Agricultura Brasileira (AGRIANUAL, 2007), em 2006 o Brasil ocupou a quarta posição na produção mundial de abacaxis, com 1,42 milhões de toneladas, distribuídas principalmente nas regiões Nordeste, Sudeste e Norte (37,6\%, 35,9\% e 21,5\%, respectivamente).

No Brasil, as principais cultivares produzidas são 'Smooth Cayenne', 'Pérola' e 'Boituva'. A cultivar 'Smooth Cayenne' apresenta polpa amarela e maior acidez em relação às demais, sendo considerada mais adequada para a industrialização, enquanto as cultivares 'Pérola' e 'Boituva' são comercializadas principalmente in natura, apresentando menor acidez e coloração da polpa amarelopálida ou branca (VAILLANT et al., 2001).

Os produtos minimamente processados são semelhantes ao produto in natura quanto aos aspectos nutricionais e organolépticos, apresentando porém modificações em sua condição natural devido à aplicação de tecnologias como descascamento, corte, centrifugação e embalagem (CHITARRA, 2000). Com o processamento mínimo do abacaxi obtêm-se produto com características sensoriais e nutricionais praticamente inalteradas, de grande conveniência para o consumo imediato e em pequenas porções individuais (BASTOS et al., 2000). Entretanto, o processamento mínimo pode reduzir a vida útil de frutas e hortaliças devido ao aumento da superfície exposta e injúrias, disponibilizando nutrientes para microrganismos indesejáveis, além da liberação de enzimas endógenas e aumento da taxa de respiração (BONNAS, 2002; ROSA e CARVALHO, 2000; WILEY, 1997). Assim, outras tecnologias devem ser utilizadas conjuntamente ao processamento mínimo (resfriamento, atmosfera modificada, radiação ionizante, utilização de filmes comestíveis, ceras) visando a otimização do processo.

A irradiação de alimentos tem recebido atenção crescente, devido às vantagens que apresenta em relação aos métodos convencionais de processamento de alimentos (VERRUMA-BERNARDI e SPOTO, 2003). A irradiação pode inibir o brotamento de raízes e tubérculos, a infestação de parasitas e insetos, além de reduzir podridões e microrganismos patogênicos, aumentando a vida útil de frutas e hortaliças in natura ou processadas. Assim, a irradiação complementa outras técnicas de conservação, podendo ser realizada após a embalagem do produto, reduzindo a possibilidade de recontaminação (TAPE, 1996).

O processo de irradiação acarreta poucas alterações químicas nos alimentos, que não são nocivas ou perigosas. A variação do valor nutritivo causada pela irradiação depende de vários fatores, dentre os quais a dose de exposição, o tipo de alimento, sua embalagem e condições do tratamento (tais como a temperatura durante a irradiação e o tempo de armazenamento). Desta forma, o tratamento de alimentos por irradiação não altera fisicamente a aparência, a forma ou a temperatura dos produtos se devidamente controlado (VERRUMA-BERNARDI e SPOTO, 2003).

Este trabalho teve por objetivo avaliar os efeitos da radiação ionizante com doses de 1 e 2 kGy sobre os atributos físico-químicos (sólidos solúveis, pH, acidez total titulável, firmeza e coloração) e sensoriais (aparência, textura, sabor e aroma) de abacaxis cv. 'Smooth Cayenne' minimamente processados durante o período de armazenamento refrigerado.

\section{MATERIAL E MÉTODOS}

A pesquisa foi desenvolvida no Departamento de Agroindústria Alimentos e Nutrição, da Escola Superior de Agricultura "Luiz de Queiroz" (ESALQ-USP), em Piracicaba, SP. Foram utilizados abacaxis cv. 'Smooth Cayenne' adquiridos em ponto comercial e transportados para o laboratório de processamento para a montagem do experimento. 


\subsection{PROCESSAMENTO DO ABACAXI}

Os abacaxis foram lavados e sanificados com solução de hipoclorito de sódio com $200 \mathrm{mg} \cdot \mathrm{L}^{-1}$ de cloro ativo em pH ajustado a 7,0, sob temperatura de $5 \pm 1^{\circ} \mathrm{C}$ durante 15 minutos. Em seguida, os frutos foram descascados manualmente e a polpa fatiada em rodelas de aproximadamente $13 \mathrm{~cm}$ de diâmetro e $1 \mathrm{~cm}$ de espessura, com o auxílio de fatiador com lâmina de aço inoxidável sem marca comercial, confeccionado especificamente para realização do experimento. As fatias foram imersas durante 3 minutos em solução de hipoclorito de sódio com $20 \mathrm{mg}^{-L^{-1}}$ de cloro ativo em pH ajustado a 7,0, sob temperatura de $5 \pm 1^{\circ} \mathrm{C}$, sendo em seguida drenadas por 5 minutos (SARZI, DURIGAN e ROSSI JUNIOR, 2002). As fatias foram acondicionadas em bandejas de poliestireno expandido com $15 \mathrm{~cm}$ de diâmetro $\times 2 \mathrm{~cm}$ de altura (2 fatias/bandeja), embaladas com filme plástico de policloreto de vinila (PVC) e armazenadas sob temperatura de $5 \pm 1^{\circ} \mathrm{C}$ e umidade relativa (UR) de $95 \%$ por 12 horas. Após esse período, as amostras foram irradiadas com doses de 1 kGy e 2 kGy em irradiador de Cobalto-60 Gammabeam 650, no Laboratório de Irradiação de Alimentos e Radioentomologia do Centro de Energia Nuclear na Agricultura (CENA/USP), sendo o controle não-irradiado. As amostras foram novamente armazenadas a $5 \pm 1^{\circ} \mathrm{C}$, com $95 \%$ UR, e analisadas no primeiro, terceiro e sexto dias após a irradiação (dias 1, 3 e 6, respectivamente) para a caracterização físico-química e sensorial dos abacaxis minimamente processados.

\subsection{ANÁLISES FÍSICO-QUÍMICAS}

Os Sólidos Solúveis (SS) foram determinados por leitura direta em refratômetro manual ATAGO, com correção de temperatura, utilizando-se o suco do abacaxi sem diluição (resultados expressos em ${ }^{\circ}$ Brix) conforme as normas do Instituto Adolfo Lutz (IAL, 1985).

Determinou-se o pH das amostras por potenciometria em aparelho DIGIMED DMPH-2 a $20^{\circ} \mathrm{C}$, com resultados expressos em unidade de $\mathrm{pH}$, segundo técnica fornecida pela AOAC (1997).

Determinou-se a Acidez Total Titulável (ATT) pela técnica preconizada pela AOAC (1997), expressa em \% de ácido cítrico (mg $\left.100 \mathrm{~g}^{-1}\right)$.

Mediu-se a Firmeza das amostras por resistência ao penetrômetro de sensibilidade 1,5 Newton, marca Wagner Dial Force FDN 2, com resultados expressos em Newton (N) (MODA et al., 2005).

Determinou-se a Coloração das amostras pelos valores de $\mathrm{L}$, a e b, obtidos com colorímetro Minolta CR-400 previamente calibrado, de acordo com padrões pré-estabelecidos (BIBLE e SINGHA, 1993).

\subsection{ANÁLISE SENSORIAL}

A aplicação do teste de preferência foi realizada no laboratório de análise sensorial, utilizandose escala hedônica de nove pontos para os quesitos aroma, aparência, sabor e textura. Os julgadores foram selecionados a partir da aplicação de questionário simplificado, avaliando-se a faixa etária, condições de saúde e afinidade com o produto.

A avaliação sensorial foi realizada em cabines individuais, com as amostras apresentadas aos julgadores em recipientes codificados com algarismos de três dígitos, juntamente com a ficha de avaliação ancorada nos extremos pelos termos "gostei extremamente (9) e desgostei extremamente (1)". As amostras foram avaliadas por 50 julgadores não-treinados em cada período de análise (DUTCOSKY, 1996).

\subsection{DELINEAMENTO ESTATÍSTICO}

O experimento foi conduzido inteiramente ao acaso, utilizando-se análise de variância e o método de análise de superfícies de resposta para as variáveis que apresentaram significância a 5\% (KHURI, 1996; MONTGOMERY e MYERS, 2002). 


\section{RESULTADOS E DISCUSSÃO}

Utilizando-se do método de análise de superfície de resposta foram gerados modelos matemáticos e seus respectivos coeficientes de determinação $\left(R^{2}\right)$ e correlação $(R)$ para os parâmetros avaliados que apresentaram diferença significativa a 5\% (Tabela 1). Apesar de alguns coeficientes de determinação serem aparentemente baixos, convém ressaltar que os coeficientes de correlação linear entre os valores observados e os estimados pelos modelos foram sempre superiores a 0,71 demonstrando o bom ajuste dos modelos considerados. Através dos modelos foram gerados gráficos de superfície de resposta e gráficos de contorno para os parâmetros que apresentaram dependência em relação à dose aplicada e/ou ao dia de avaliação, considerando-se o nível de significância de 5\%.

\section{TABELA 1 - MODELOS DE SUPERFÍCIE DE RESPOSTA, COEFICIENTES DE DETERMINAÇÃO $\left(R^{2}\right)$ E CORRELAÇÃO (R) PARA AS VARIÁVEIS OBSERVADAS NO EXPERIMENTO EM QUE HÁ DEPENDÊNCIA EM RELAÇÃO À DOSE DE RADIAÇÃO E/OU AO NÚMERO DE DIAS APÓS A RADIAÇÃO, CONSIDERANDO-SE O NÍVEL DE SIGNIFICÂNCIA 5\%}

\begin{tabular}{|c|c|c|}
\hline Mo delos & $\mathbf{R}^{2}$ & $\mathbf{R}$ \\
\hline $\begin{array}{l}\mathrm{SS}=12,65474+1,121053 \mathrm{Dose}-0,603977 \mathrm{Dia}-0,489474 \mathrm{Dose}^{2}-0,176316 \\
\text { Dose.Dia +0,075556 Dia + 0,086842 } \mathrm{Dose}^{2} \text {. Dia }\end{array}$ & 0,77 & 0,88 \\
\hline $\begin{aligned} \mathrm{pH}= & 4,246842+0,123684 \text { Dose }-0,016053 \text { Dia }-0,070789 \text { Dose }^{2} \\
& -0,187105 \text { Dose.Dia }+0,098487 \text { Dose }^{2} . \text { Dia }\end{aligned}$ & 0,55 & 0,74 \\
\hline \multicolumn{3}{|l|}{ ATT $=0,773427+0,020772$ Dia $+0,373333$ Dose $-0,170667$ Dose $^{2}$} \\
\hline$L=43,695+6,884444 \mathrm{Dia}-1.033611 \mathrm{Dia}^{2}$ & 0,51 & 0,71 \\
\hline Firmeza $=1,143333-0,615$ Dose $+0,298333$ Dose $^{2}$ & 0,50 & 0,71 \\
\hline Aroma $=\left(15,7709-4,947138 \text { Dose }+1,678551 \mathrm{Dose}^{2}\right)^{1 / 1,4}$ & 0,55 & 0,74 \\
\hline $\begin{aligned} \text { Sabor }= & \left(57,1533+3,4294 \mathrm{Dia}-5,6800 \mathrm{Dose}-0,9028 \mathrm{Dia}^{2}\right. \\
& \left.-4,0150 \text { Dia.Dose }+0,7550 \mathrm{Dia}^{2} \text {. Dose }\right)^{12}\end{aligned}$ & 0,65 & 0,81 \\
\hline $\begin{array}{l}\text { Textura }=\left(88,1487+4,5790 \text { Dia }-26,7036 \text { Dose }+14,9782 \text { Dose }^{2}\right. \\
\left.? 1,3282 \text { Dia }^{2}-2,5455 \text { Dia.Dose }-3,9985 \text { Dia.Dose }+1,6101 \mathrm{Dia}^{2} . \text { Dose }\right)^{1 / 22}\end{array}$ & 0,65 & 0,81 \\
\hline Aparência $=(60,1768-2,1227 \text { Dia }-7,2032 \text { Dose }+1,2739 \text { Dia.Dose })^{1 / 2}$ & 0,56 & 0,75 \\
\hline
\end{tabular}

\subsection{ANÁLISES FÍSICO-QUÍMICAS}

\subsubsection{Sólidos solúveis (SS)}

Os sólidos solúveis (SS) representam os compostos solúveis em água, sendo parâmetro importante na determinação da qualidade do fruto. A redução no teor de SS varia com a taxa de respiração, uma vez que são utilizados no processo respiratório durante o período pós-colheita dos frutos (SANTOS, 2002). FIGUEIREDO, QUEIROZ e NORONHA (2003) obtiveram valores médios de 13,40 a $14,60^{\circ}$ Brix para abacaxi cv. 'Smooth Cayenne' minimamente processado, enquanto SANTOS (2002) registrou valores médios de 12 a 14,4 Brix para abacaxi cv. 'Pérola' minimamente processado e armazenado a $5^{\circ} \mathrm{C}$. 
Neste trabalho observou-se variação dos sólidos solúveis (SS) em função da dose de radiação e período de avaliação (Figura 1), com os maiores valores registrados para as doses de 1 e 2 kGy no dia 1 (12,6 e 12,4 ${ }^{\circ}$ Brix, respectivamente). Durante a segunda avaliação (dia 3), todos os tratamentos apresentaram redução significativa dos sólidos solúveis com o controle apresentando o menor valor (11,4 ${ }^{\circ}$ Brix). Ao final do período de armazenamento (dia 6), o controle apresentou o menor valor observado (11,6 ${ }^{\circ}$ Brix) enquanto as amostras irradiadas mantiveram a média da segunda avaliação. Os valores obtidos em todos os tratamentos foram inferiores em relação à literatura citada, podendo esse fato estar correlacionado ao ponto de colheita dos abacaxis cv. 'Smooth Cayenne'.

\section{$3.1 .2 \mathrm{pH}$}

$\mathrm{O}$ pH determina a concentração hidrogeniônica de soluções e relaciona-se inversamente com a acidez total titulável das amostras. Os ácidos orgânicos são produtos intermediários do metabolismo respiratório das frutas, sendo normalmente ácidos na reação e ocorrendo em solução. Desta forma, pode-se correlacionar a queda no teor de ATT com o aumento do $\mathrm{pH}$ da solução durante o amadurecimento de frutas tropicais (FENEMA, 1985).

Em abacaxis, os valores de pH oscilam entre 3,0 e 4,0 de acordo com ANDRADE (1999) e THÉ (2001). SANTOS (2002) obteve valores de pH entre 3,5e 4,1 para abacaxi cv. 'Pérola' minimamente processado e armazenado a $5^{\circ} \mathrm{C}$ durante 10 dias. Já SANTOS et al. (2005) registraram o valor médio de 3,6 para abacaxi cv. 'Pérola' minimamente processado, armazenado a $5^{\circ} \mathrm{C}$ durante 10 dias. Por outro lado, FIGUEIREDO, QUEIROZ e NORONHA, (2003) encontraram valores médios de pH entre 2,82 e 3,83 para abacaxi cv. 'Smooth Cayenne' minimamente processado e armazenado.

Observou-se variação do pH em função da dose de radiação absorvida e período de avaliação (Figura 1), sendo que o controle e as amostras irradiadas com $2 \mathrm{kGy}$ obtiveram desempenho similar na manutenção do pH durante o período de armazenamento (valores médios de 4,23 a 4,15 e 4,21 a 4,23 , respectivamente). Também verificou-se redução significativa do $\mathrm{pH}$ ao longo do período de armazenamento nas amostras irradiadas com $1 \mathrm{kGy}(4,22$ a 3,70), podendo ser correlacionada ao aumento da acidez total titulável (ATT) observado nesse tratamento.

\subsubsection{Acidez total titulável (ATT)}

A acidez total titulável representa a soma dos ácidos orgânicos livres e complexados dos frutos, expresso em porcentagem do ácido predominante. Esse valor aumenta durante o crescimento do fruto até seu completo desenvolvimento fisiológico, quando então começa a decrescer conforme amadurece (GONÇALVES, 1998). A teoria mais aceita para esse comportamento é a de que durante o processo respiratório ocorre a oxidação desses ácidos, utilizados como substrato no ciclo de Krebs (FENEMA, 1985).

Observou-se, de acordo com a Figura 1, que a acidez total titulável (ATT) aumentou durante o período de armazenamento em todos os tratamentos, com valores entre 0,8 a 1,1\%. O controle apresentou os menores valores de ATT em todos os períodos de avaliação $(0,8$ a $0,85 \%)$, diferindo das amostras irradiadas com 1 e 2 kGy, que apresentaram valores de 1,0 a 1,10\% e 0,9 a 1,0\%, respectivamente. Airradiação das amostras contribuiu para a elevação da ATT durante o armazenamento do abacaxi minimamente processado, notadamente na dose de $1 \mathrm{kGy}$, podendo ser correlacionada com a redução do $\mathrm{pH}$ anteriormente citado para esse tratamento.

SANTOS et al. (2005) também observaram o aumento da ATT em abacaxi cv. 'Pérola' minimamente processado e armazenado a $5^{\circ} \mathrm{C}$ durante 10 dias, com valores médios de 0,53 a $0,66 \%$. Já FIGUEIREDO, QUEIROZ e NORONHA (2003) constataram redução da ATT em abacaxi cv. 'Smooth Cayenne' minimamente processado durante o período de armazenamento a $5^{\circ} \mathrm{C}$, com valores médios de 0,45 a $0,36 \%$.

Neste trabalho foram encontrados valores de ATT superiores à literatura citada, indicando maior acidez das amostras avaliadas. Esse fato pode ter ocorrido em função da cultivar utilizada e do 
estágio de maturação dos frutos, uma vez que a acidez no abacaxi pode variar entre diferentes cultivares, entre frutos do mesmo cultivar e também entre secções do mesmo fruto (CARVALHO e BOTREL, 1996 ; SALUNKE e DESAI, 1984).

\section{FIGURA 1 - GRÁFICOS DE CONTORNOS E SUPERFÍCIES DE RESPOSTAS PARA AS VARIÁVEIS SÓLIDOS SOLÚVEIS (SS), pH E ACIDEZ TOTAL TITULÁVEL (ATT) COM DEPENDÊNCIA EM RELAÇÃO À DOSE DE RADIAÇÃO E AO NÚMERO DE DIAS APÓS A IRRADIAÇÃO AO NÍVEL DE SIGNIFICÂNCIA DE 5\%}
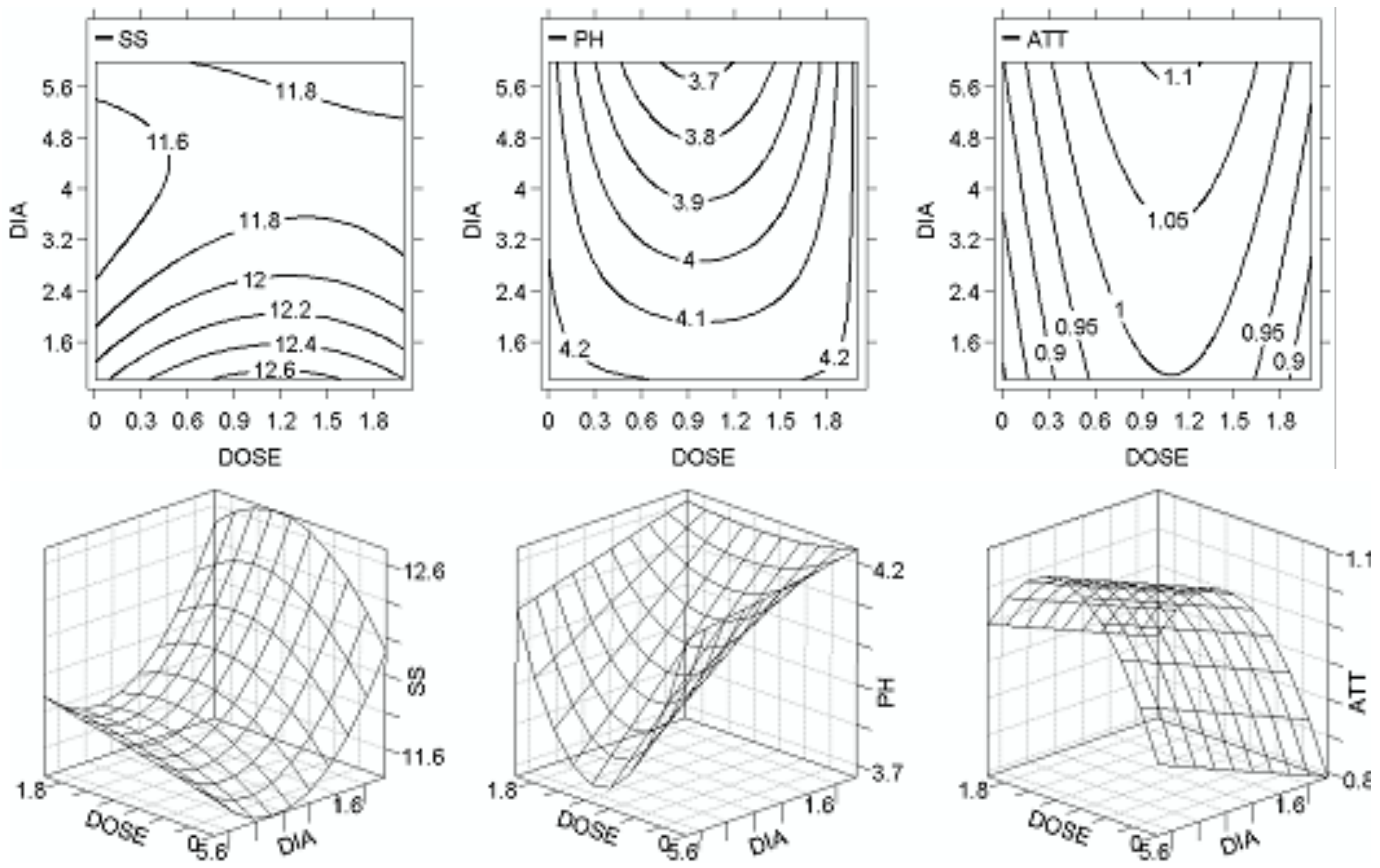

\subsection{ANÁLISES FÍSICAS}

\subsubsection{Firmeza}

A firmeza dos produtos vegetais resulta da natureza das células do parênquima e dos demais componentes estruturais das paredes celulares, tais como celulose, hemicelulose, lignina e substâncias pécticas. Trata-se de característica física de grande importância, podendo ser reduzida com a maturidade vegetal e interferindo diretamente na aceitabilidade dos produtos. Normalmente, a perda da firmeza pode ser atribuída ao amolecimento das camadas inter-lamelares e à ruptura da parede celular com a solubilização de sólidos hidrossolúveis (BEZERRA e CHITARRA, 1992).

A redução da firmeza no processamento mínimo pode ser justificada pelo descascamento e corte que causam danos e rupturas nos tecidos celulares, podendo acelerar as reações enzimáticas, a fermentação ácido-lática e alterações fisiológicas como, o aumento da taxa de respiração e produção de etileno (CISNEROS-ZEVALLOS, SALTVEIT e KROCHTA, 1995).

Verificou-se redução da firmeza nas amostras irradiadas (Figura 2), independentemente do período de armazenamento. O controle obteve os maiores valores de firmeza $(1,15 \mathrm{~N})$, encontrando-se valores intermediários para as amostras irradiadas com $2 \mathrm{kGy}(1,05 \mathrm{~N})$ e os menores valores para a dose de $1 \mathrm{kGy}(0,77 \mathrm{~N})$. Esse fato pode ter ocorrido em função da quebra das cadeias poliméricas pela radiação ionizante com a transformação da protopectina em pectina (mais solúvel), resultando na perda da textura e turgidez celulares (KING JR. e BOLIN, 1989; PROCTOR e CAYGILL, 1985). 


\subsubsection{Coloração}

A luminosidade das amostras (valor $\mathrm{L}$ ) variou somente em função do período de avaliação. Os tratamentos controle, 1 e 2 kGy apresentaram as maiores médias no dia 3 (53,0; 57,1 e 55,1, respectivamente) que decresceram novamente até o dia 6 (Figura 2). Esses resultados indicam o clareamento das amostras durante o período de armazenamento em todos os tratamentos, fato também observado por BONNAS (2002) em abacaxi cv. 'Smooth Cayenne' minimamente processado. Os valores de a e b não foram submetidos à modelagem de superfície de resposta por não apresentarem significância a $5 \%$.

\section{FIGURA 2 - GRÁFICOS DE CONTORNOS E SUPERFÍCIES DE RESPOSTAS PARA AS VARIÁVEIS LUMINOSIDADE (L) E FIRMEZA COM DEPENDÊNCIA EM RELAÇÃO AO NÚMERO DE DIAS APÓS A RADIAÇÃO E À DOSE DE RADIAÇÃO AO NÍVEL DE SIGNIFICÂNCIA DE 5\%}
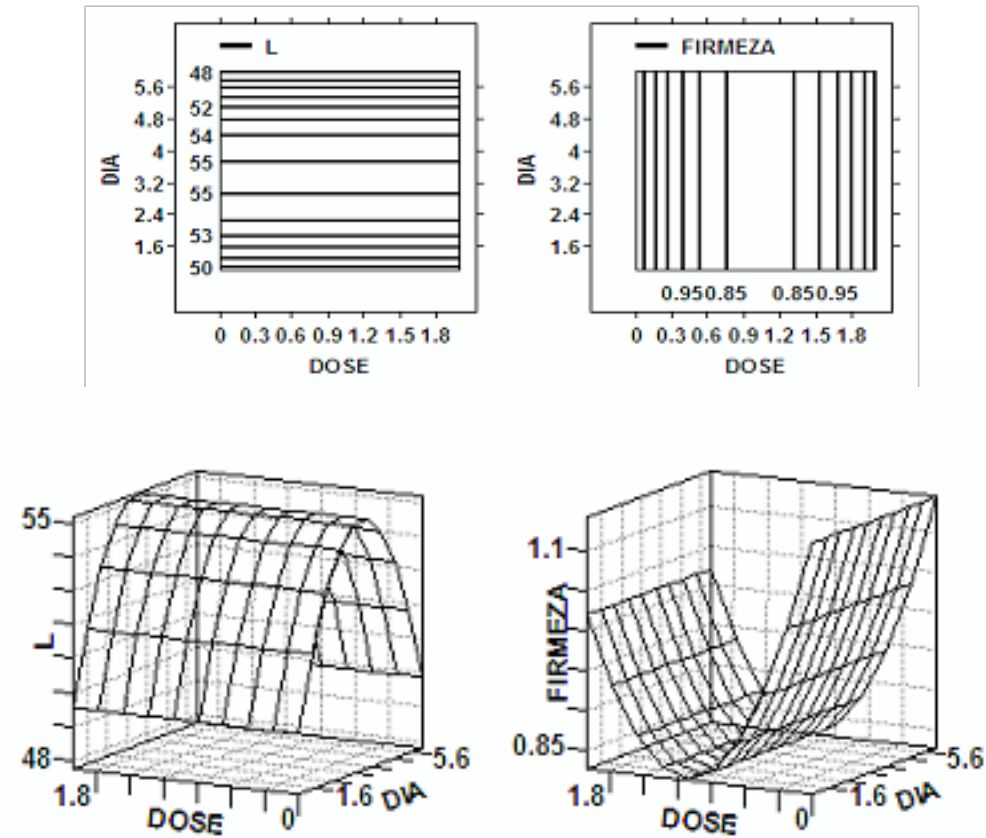

3.3 ANÁLISE SENSORIAL

De acordo com MEILGAARD, VANCE e CIVILLE (1999) pode-se inferir a preferência dos consumidores em função dos valores relativos de aceitabilidade obtidos nos testes afetivos, ou seja, as amostras com maiores notas serão as mais preferidas pelos julgadores. Deste modo, neste trabalho considerou-se como adequada a região dos modelos de superfície referentes às maiores notas dos atributos sensoriais avaliados (Figura 3).

Observou-se que o atributo aroma variou somente em função da dose de radiação absorvida, independentemente do período de armazenamento. O controle apresentou o maior valor médio durante o experimento $(7,4)$, equivalendo à opção "gostei moderadamente" da ficha de avaliação sensorial. As amostras irradiadas com 1 e 2 kGy apresentaram valores médios significativamente menores durante o período de armazenamento (6,2 e 6,4, respectivamente), equivalendo à opção "gostei ligeiramente".

As notas obtidas para o atributo sabor variaram em função da irradiação das amostras e do período de avaliação. O maior valor médio foi obtido para o controle no dia $1(8,25)$ e o menor valor para 
a dose de 1 kGy no dia $3(7,0)$, correspondendo às opções "gostei muito" e "gostei moderadamente", respectivamente.

A firmeza variou em função da dose de radiação e período de avaliação, sendo o maior valor observado no dia 1 para o controle $(6,9)$ e o menor valor no dia 3 para as amostras irradiadas com 2 kGy $(5,4)$. A aparência também variou em função da dose de radiação e período de avaliação, sendo o maior valor registrado para o controle no dia $1(6,0)$ que corresponde à opção "gostei ligeiramente".

As amostras irradiadas com 1 e $2 \mathrm{kGy}$ evidenciaram resultados inferiores ao controle nos atributos sensoriais avaliados (aroma, sabor, textura e aparência), apesar dos valores obtidos estarem acima do limite de aceitabilidade (nota 5) durante todo o experimento.

\section{FIGURA 3 - GRÁFICOS DE CONTORNOS E SUPERFÍCIES DE RESPOSTAS PARA AROMA, SABOR, TEXTURA E APARÊNCIA COM DEPENDÊNCIA EM RELAÇÃO À DOSE DE RADIAÇÃO E AO NÚMERO DE DIAS APÓS A RADIAÇÃO AO NÍVEL DE SIGNIFICÂNCIA DE 5\%}
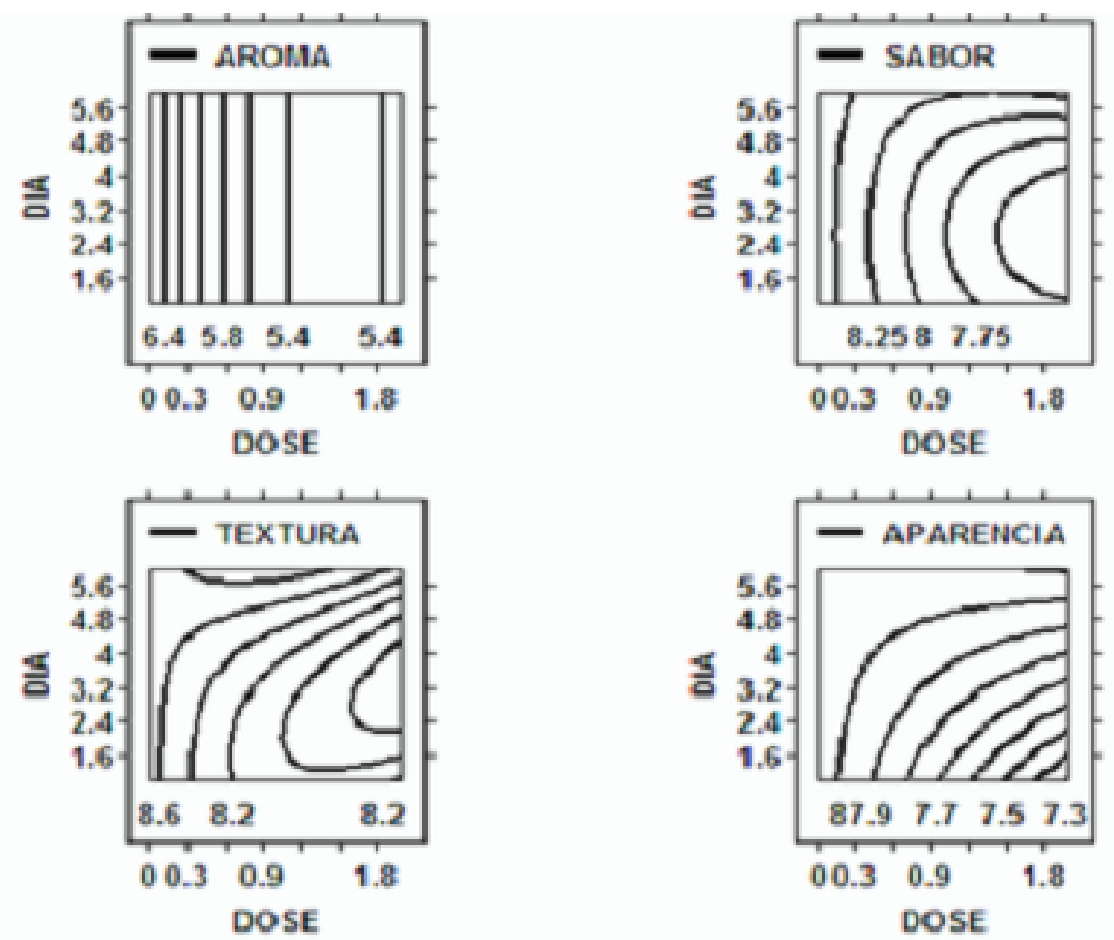

O teor de sólidos solúveis foi maior na primeira avaliação para as doses de 1 e 2 kGy, porém decaiu em todos os tratamentos com o decorrer do período de armazenamento.

Observou-se aumento da acidez total titulável em todos os tratamentos durante o período de armazenamento, notadamente na dose $1 \mathrm{kGy}$, sendo que o controle apresentou os menores valores de acidez em todos os períodos. Também foi observada redução significativa do $\mathrm{pH}$ durante o período de avaliação nas amostras irradiadas com 1 kGy, podendo ser correlacionada ao aumento da acidez nesse tratamento.

A irradiação com 1 e 2 kGy não afetou a coloração dos abacaxis minimamente processados no período final de avaliação, apesar das amostras apresentarem aumento da luminosidade (L) no dia 3 em todos os tratamentos.

A firmeza das amostras irradiadas foi reduzida em relação ao controle, independentemente do período de armazenamento, notadamente nos abacaxis irradiados com 1 kGy.

O controle apresentou as melhores notas durante a avaliação sensorial em todos os períodos, sendo melhor aceito pelos julgadores nos quesitos avaliados. 
A irradiação de abacaxi cv. 'Smooth Cayenne' minimamente processado com 1 kGy não alcançou resultados satisfatórios para as análises de sólidos solúveis, acidez total titulável, pH, firmeza e sensorial. O controle apresentou, de maneira geral, os melhores resultados, enquanto as amostras irradiadas com 2 kGy apresentaram resultados intermediários na maioria das análises realizadas.

Sugere-se avaliar o abacaxi minimamente processado e irradiado com 2 kGy mediante análise da atividade respiratória e enzimática, síntese de etileno e análises microbiológicas, uma vez que são parâmetros importantes para a qualidade pós-colheita de frutas e hortaliças in natura ou processadas.

\section{ABSTRACT \\ PHYSICAL-CHEMICAL AND SENSORIAL QUALITY OF IRRADIATED AND MINIMALLY PROCESSED PINEAPPLE}

The present work had as objective to monitor the physical-chemical and sensorial quality of pineapple cV. "Smooth Cayenne" minimally processed and submitted to gamma radiation. The fruits were peeled, sliced and sanitized with $20 \mathrm{mg}^{-\mathrm{L}^{-1}}$ active chlorine. The slices were packed in polystyrene trays covered with vinyl polichloride flexible film (VPC) and irradiated with 1 and $2 \mathrm{kGy}$, being the control non irradiated. The samples were stored at temperature of $5 \pm 1^{\circ} \mathrm{C}$ and evaluated in the first, third and sixth days of storage for color, firmness, soluble solids (SS), total titratable acidity, $\mathrm{pH}$ and sensorial analysis. The control presented the smallest values of acidity and $\mathrm{pH}$ maintenance in all evaluations, while the soluble solids was higher in the first evaluation for the doses of 1 and $2 \mathrm{kGy}$, declining with storage time. The irradiation didn't affect the color of minimally processed pineapples in the period of the evaluation, although reduced the firmness of the samples in the dose of $1 \mathrm{kGy}$. The control presented the best grades in sensorial evaluations for the attributes of aroma, taste, texture and appearance. In a general way, the best results were observed for non irradiated minimally processed pineapple (control), being that the irradiated samples with $1 \mathrm{kGy}$ obtained inadequate results for the analysis of soluble solids, total titratable acidity, $\mathrm{pH}$, firmness and sensorial.

KEY-WORDS: PINEAPPLE; MINIMAL PROCESSING; IRRADIATION; PRESERVATION.

\section{REFERÊNCIAS}

1 ANDRADE, A.P.S. Padrões de identidade e qualidade para o abacaxi, a goiaba e o mamão. Viçosa, 1999. 124 p. Dissertação (Mestrado em Ciência e Tecnologia de Alimentos) - Universidade Federal de Viçosa.

2 AGRIANUAL 2007. Anuário da agricultura brasileira. São Paulo: FNP Consultoria e Comércio, 2007. p. 149-158.

3 AOAC. Association of Official Analytical Chemistry. Official methods of analysis of AOAC International. $14^{\text {th }}$ ed. Washington, 1997.

4 BASTOS, M.S.R.; SOUZA FILHO, M.S.M.; ALVES, R.E.; FILGUEIRAS, H.A.; BORGES, M.F. Processamento mínimo de melão e abacaxi. In: ENCONTRO DE PROCESSAMENTO MÍNIMO DE FRUTAS E HORTALIÇAS, 2000, Viçosa. Anais... Viçosa: UFV, 2000. p.89-94.

5 BEZERRA, R.M.N.; CHITARRA, M.I.F. Textura e pectina em cenoura branqueada e congelada. Ciência e Tecnologia de Alimentos, v.12, n.2, p.134-139, 1992.

6 BIBLE, B.B.; SINGHA, S. Canopy position influences CIELAB coordinates of peach color. HortScience, v.28, n.10, p.992-993, 1993.

7 BONNAS, D.S. Qualidade do abacaxi cv. 'Smooth Cayenne' minimamente processado, embalado sob atmosfera modificada. Lavras, 2002. 100 p. Tese (Doutorado em Ciências) - Universidade Federal de Lavras.

8 CARVALHO, V.D.; BOTREL, N. Características da fruta para exportação. In: GORGATTI NETO, A. et al. Abacaxi para exportação: procedimentos de colheita e pós-colheita. Brasília: EMBRAPA-SP, 1996. 41 p. (FRUPEX. Publicações Técnicas, 23).

9 CHITARRA, M.I. Processamento mínimo de frutos e hortaliças. Lavras: UFLA/FAEPE, 2000. 119 p. (Textos acadêmicos da Universidade Federal de Lavras).

10 CISNEROS-ZEVALLOS, L.; SALTVEIT, M.E.; KROCHTA, J.M. Mechanism of surface white discoloration of peeled (minimally processed) carrots during storage. Journal of Food Science, v.60, n.2, p.320-323, 1995.

11 DUTCOSKY, S.D. Análise sensorial de alimentos. Curitiba: Champagnat, 1996. 123 p. 
13 FIGUEIREDO, R.M.F.; QUEIROZ, A.J.M.; NORONHA, M.A.S. Armazenamento de abacaxi minimamente processado. Revista Brasileira de Produtos Agroindustriais, n.1, p.95-103, 2003.

14 GONÇALVES, N.B. Efeito da aplicação de cloreto de cálcio associado ao tratamento hidrotérmico sobre a composição química e suscetibilidade ao escurecimento interno do abacaxi cv. 'Smooth Cayenne'. Lavras, 1998. 101 p. Tese (Doutorado em Ciências) - Universidade Federal de Lavras.

15 IAL. Instituto Adolfo Lutz. Normas analíticas do Instituto Adolfo Lutz: métodos químicos e físicos para análise de alimentos. 3. ed. São Paulo: Nobel, 1985. v.1. 533 p.

16 KHURI, A.I.; CORNELL, J.A. Response surfaces, designs and analysis. $2^{\text {nd }}$ ed.New York: Marcell Dekker, 1996. $510 \mathrm{p}$.

17 KING JR., A.D.; BOLIN, H.R. Physiological and microbiological storage stability of minimally processed fruits and vegetables. Food Technology, v.2, p.124-128, 1989.

18 MEILGAARD, M.; VANCE, G.; CIVILLE, B.T.C. Sensory evaluation techniques. $3^{\text {rd }}$ ed. Boca Raton: CRC Press, 1999. p. 231-255.

19 MODA, E.M.; SPOTO, M.H.F.; HORII, J.; ZOCCHI, S.S. Uso de peróxido de higrogênio e ácido cítrico na conservação de cogumelos Pleurotus sajor-caju 'in natura'. Ciência e Tecnologia de Alimentos, v.25, n.2, p.291-296, 2005.

20 MONTGOMERY, D.C.; MYERS, R.H. Response surface methodology: process and product optimization using designed experiments. $2^{\text {nd }}$ ed. New York: John Wiley, 2002. 798 p.

21 PROCTOR, F.J.; CAYGILL, J.C. Ethylene in commercial postharvest handling of tropical fruit. London: Butterworth Scientific, 1985. 512 p.

22 ROSA, O.O.; CARVALHO, E.P. Características microbiológicas de frutos e hortaliças minimamente processadas. Boletim da Sociedade Brasileira de Ciência e Tecnologia, v.34, n.2, p.84-92, 2000.

23 SALUNKE, D.K.; DESAI, B.B. Postharvest biotechnology of fruits. Boca Raton: CRC Press, 1984. v.2, 194 p.

24 SANTOS, J.C.B. Influência da atmosfera modificada ativa sobre a qualidade do abacaxi 'Pérola' minimamente processado. Lavras, 2002. 74 p. Dissertação (Mestrado em Ciência e Tecnologia de Alimentos) Universidade Federal de Lavras.

25 SANTOS, J.B.C.; VILAS-BOAS, E.V.B.; PRADO, M.E.T.; PINHEIRO, A.C.M. Avaliação da qualidade do abacaxi 'Pérola' minimamente processado armazenado sob atmosfera modificada. Ciência Agrotécnica, v.29, n.2, p.353-361, 2005.

26 SARZI, B.; DURIGAN, J. F.; ROSSI JUNIOR, O. D. Temperatura e tipo de preparo na conservação de produto minimamente processado de abacaxi 'Pérola'. Revista Brasileira de Fruticultura, Jaboticabal, v. 24, n. 2, p. 376-380, 2002.

27 TAPE, N. W. Protegendo nossas colheitas. Vienna: ICGFI, 1996.

28 THÉ, P.M.P. Efeitos da associação de tratamento hidrotérmico, cloreto de cálio e atmosfera modificada sobre o escurecimento interno e qualidade do abacaxi cv. 'Smooth Cayenne'. Lavras, 2001.128 p. Dissertação (Mestrado em Ciência e Tecnologia de Alimentos) - Universidade Federal de Lavras.

29 VAILLANT, F.; MILLAN, A.; DORNIER, M.; DECLOUX, M.; REYNES, M. Strategy for economical optimization of the clarification of pulpy fruit juices using crossflow microfiltration. Journal of Food Engineering, v.48, p.83-90,2001.

30 VERRUMA-BERNARDI, M.R.; SPOTO, M.H.F. Efeito da radiação gama sobre o perfil sensorial do suco de laranja. Ciência e Tecnologia de Alimentos, v.23, n.1, p.23-29, 2003.

31 WILEY, R.C. Frutas y hortalizas minimamente processadas e refrigeradas. Zaragoza: Acríbia, 1997. 361 p. 